\title{
Comparative Study of Two In Vitro Methods for Assessing Drug Absorption: Sartorius SM 16750 Apparatus Versus Everted Gut Sac
}

\author{
Mohamed Ali Lassoued ${ }^{\mathrm{a}}$, Fathia Khemiss ${ }^{\mathrm{b}}$, Souad Sfar ${ }^{\mathrm{a}}$ \\ ${ }^{\text {a }}$ Laboratory of Galenic Pharmacy, Faculty of Pharmacy of Monastir, University of Monastir, 5000 Monastir, Tunisia. \\ ${ }^{\mathrm{b}}$ Laboratory of Human Physiology, Faculty of Dental Medicine of Monastir, University of Monastir, 5000 Monastir, \\ Tunisia.
}

Received, December 20, 2010; Revised, February 10, 2011; Accepted, April 6, 2011; April 6, 2011

\begin{abstract}
Purpose. Oral drug administration remains the most common and most convenient way used in clinical therapy. The availability of a simple, rapid, economic and reproducible in vitro method to assess the rate, extent and mechanism of intestinal drug absorption is a very helpful tool. The purpose of this study was to compare the performance of Sartorius SM 16750 Absorption Simulator apparatus to Everted Gut Sac (EGS) technique in terms of predicting drug permeability. Methods. Permeation studies across these two in vitro models were performed with six drugs selected across the Biopharmaceutics Classification System (BCS) categories: tramadol (class I of BCS), doxycycline (class I of BCS), diclofenac (class II of BCS), clopidogrel (class II of BCS), metformin (class III of BCS) and chlorothiazide (class IV of BCS). Results. Apparent permeability coefficient $\left(\mathrm{P}_{\text {app }}\right)$ and diffusion profiles obtained with EGS and Sartorius SM 16750 apparatus were similar for diclofenac and metformin, whereas, we noticed significant differences $(\mathrm{p} \leq 0.05)$, for tramadol, doxycycline, clopidogrel and chlorothiazide. Conclusion. Compared to Everted Gut Sac model, Sartorius SM 16750 absorption simulator apparatus seems to have limited application for the assessment of intestinal drug absorption since it does not take into consideration the involvement of others processes than the passive transcellular pathway as mechanism of drug absorption.
\end{abstract}

\section{INTRODUCTION}

Oral drug administration remains the most common and the most convenient way used in clinical therapy. Solid oral drugs represent approximately $80 \%$ of the marketed dosage forms (1). Compared to other oral dosage forms, they offer many advantages: they are stable, they have a smaller bulk, their dosing is accurate, and their manufacturing is relatively easy (2). Generally, drugs administered orally are absorbed in the upper small intestine. The absorption capacity declines down the intestine and decreases markedly after the ileum, resulting in a small absorption window (3). Consequently, intestinal absorption is one of the key factors for the bioavailability of oral dosage forms. It is a complex transfer process that takes place across the epithelial mucosa and that is influenced by a variety of factors including the physicochemical properties of the drug (e.g. molecular weight and/or size, degree of ionization $\mathrm{pKa}$, solubility, oil/water partition coefficient, stereochemistry, charge distribution, chemical stability), the physiological properties of the gastrointestinal (GI) tract (e.g. gastric emptying, GI motility, area available for absorption, $\mathrm{pH}$ values in the various regions of the GI tract, blood flow), and the formulation aspects (e.g. particle size, crystal form and polymorphism, dissolution rate, absorption enhancers, tablets, capsules, solutions, etc.) $(4,5,6)$. There are 3 main mechanisms involved in the transfer of drug compounds across the intestinal epithelial mucosa: 1) The passive transcellular diffusion through the cell membrane which is the predominant route for hydrophobic drugs and which follows the concentration gradient meaning that the absorption rate is proportional to the drug concentration; 2) The passive paracellular transport through the tight junctions between the enterocytes which occurs with small hydrophilic compounds; 3) The transcellular transport which uses transporters that may function either passively or actively. (5,7-9). Several methods have been used to assess drug absorption; they include physicochemical models, in silico computational models, in situ models, in vitro models and in vivo animal models $(\mathbf{9}, \mathbf{1 0})$. Ideally, the models used for the evaluation of intestinal drug absorption and permeability should be reliable, inexpensive, fast and highly predictive $(11,12)$.

\begin{tabular}{llrr}
\hline Corresponding Author: & Mohamed & Ali Lassoued; \\
Laboratory of Pharmaceutics, Faculty of & Pharmacy of \\
Monastir, 5000 & Monastir, & Tunisia; \\
E-mail: lassoued98@yahoo.fr & &
\end{tabular}


The purpose of the present study is to compare the performances of the Sartorius SM 16750 Absorption Simulator with the Everted Gut Sac (EGS) technique in the evaluation of drug permeability. The EGS technique is a valuable in vitro procedure that can be used to assess the permeability characteristics of various drug classes $(\mathbf{8}, \mathbf{1 3})$. The bio-mimetic artificial membranes, such as those used with the Sartorius SM 16750 Simulator, represent an interesting alternative in vitro method to assess drug absorption properties. They are rapid, economic, reproducible and easy to carry out (14). For the evaluation of these two in vitro models, 6 compounds were chosen. These are: tramadol, doxycycline, diclofenac, clopidogrel, metformin and chlorothiazide. The selected drugs belong to different classes of the Biopharmaceutic Classification System (BCS) (Table 1). Tramadol, a centrally acting opioid analgesic (15) and doxycycline, an antibiotic (16), belong to class I of the BCS $(17,18)$. Diclofenac, a nonsteroidal anti-inflammatory drug (19) and clopidogrel, a thienopyridine antiplatelet agent (20), belong to class II of the BCS (21). Metformin, a biguanide antidiabetic agent (22) and chlorothiazide, a thiazide diuretic and antihypertensive agent (23), belong to class III and IV of the BCS respectively $(24,25)$. According to this classification system (26), tramadol and doxycycline are highly soluble and highly permeable drugs, diclofenac and clopidogrel are poorly soluble but highly permeable substances, metformin is a highly soluble but poorly permeable compound and chlorothiazide is a poorly soluble and poorly permeable drug.

\begin{tabular}{|c|c|}
\hline $\begin{array}{l}\text { Table 1. The } \\
\text { System (BCS): } \\
\text { the intestinal drug } \\
\text { and permeability in }\end{array}$ & $\begin{array}{l}\text { maceutic Classi } \\
\text { ng tool for pre } \\
\text { n according to so } \\
\text { s medium. }\end{array}$ \\
\hline Class I & Class II \\
\hline High solubility & Low solubility \\
\hline High permeability & High permeability \\
\hline Class III & Class IV \\
\hline High solubility & Low solubility \\
\hline Low permeability & Low permeability \\
\hline
\end{tabular}

\section{MATERIALS AND METHODS}

\section{Drugs and Chemical Reagents}

Clopidogrel hydrogenosulfate and tramadol chlorhydrate were kindly provided by Medis Laboratories (Nabeul, Tunisia); metformin chlorhydrate and chlorothiazide were provided by Siphat Laboratories (Tunis, Tunisia), doxycycline was provided by the National Drug Control Laboratory (Tunis, Tunisia) and diclofenac sodium was provided by Unimed (Sousse, Tunisia). Lauric alcohol, caprylic acid, monopotassium phosphate and disodic phosphate were purchased from Sigma Aldrich Laborchemikalien $\mathrm{GmbH}$ (Germany). $\mathrm{NaOH}$, $\mathrm{HCl}$, citric acid, $\mathrm{NaCl}, \mathrm{KCl}, \mathrm{HCO}_{3} \mathrm{Na}$, and $\mathrm{CaCl}_{2}$ were acquired from Chemi-Pharma Laboratories (Tunis,Tunisia). All chemicals and reagents used were of analytical grade. All drug solutions were freshly prepared before use.

\section{Buffer Solutions}

Buffer solutions were prepared according to the European Pharmacopoeia as follows:

\section{Buffer Solution Phosphate pH 6.8}

$77.3 \mathrm{ml}$ of disodic phosphate R $(71.5 \mathrm{~g} / \mathrm{l})$ were mixed with $22.7 \mathrm{ml}$ of citric acid solution $\mathrm{R}(21$ $\mathrm{g} / \mathrm{l})$. The $\mathrm{pH}$ of the solution was adjusted using a citric acid solution R (21 g/l) when necessary.

\section{Buffer Solution Phosphate pH 7.4}

$250 \mathrm{ml}$ of potassium phosphate were added to $393.4 \mathrm{ml}$ of $\mathrm{NaOH} 0.1 \mathrm{M}$.

\section{Diffusion Assays}

Diffusion assays were performed using a biomimetic artificial membrane and the EGS technique.

\section{The Sartorius Absorption Simulator Model}

Figure 1 shows a schematic representation of the Sartorius SM 16750 Absorption Simulator (Sartorius Membranfilter GmbH, Germany) (27). This apparatus consists of a donor compartment (A) filled with a $\mathrm{pH} 6.8$ buffer solution and a receiver compartment (B) filled with a $\mathrm{pH} 7.4$ phosphate buffer solution. Both media were maintained at $37 \pm 0.5{ }^{\circ} \mathrm{C}$ and circulated continuously on the two sides of the diffusion cell thanks to a peristaltic pump at a rate of 9.5 $\mathrm{ml} / \mathrm{min}$. The diffusion cell contains a nitrocellulose artificial membrane (OSMONICS Micronsep ${ }^{\circledR}$ model, Bioblock, France, diameter $=$ $90 \mathrm{~mm}$ and pore size $=0.45 \mu \mathrm{m}$ ). This membrane was impregnated, by immersion for 1 hour, with a lipidic mixture consisting of caprylic acid and lauric alcohol $(50: 50 \mathrm{w} / \mathrm{w})$. The excess of lipidic mixture was eliminated with absorbing paper. The percent of lipidic mixture absorption, calculated by weighing the membrane before and after 
impregnation, ranged between 90 and $110 \%$. The drug tested was added to the donor compartment, samples were withdrawn from the receptor compartment at $15,30,45,60,75,90,105$, and 120 minutes, assayed spectrophotometrically and immediately put back in the medium. The experiments were conducted 6 times for each drug. Drug absorption was expressed in percentage. No interferences were observed with the components of the membrane during the diffusion assays.

\section{The EGS Technique}

The experiments were carried out on male Wistar rats provided by Central Pharmacy of Tunis (Tunis, Tunisia). The animals were treated according to the Canadian Council on Animal Care guidelines (1984). They were kept in an animal house at standard environmental conditions. The animals were fasted for 24 hours prior to the experiment while having free access to water. Their weight ranged between 200 and $250 \mathrm{~g}$. The rats were anesthetized with ether before the experiment; the jejunum was isolated, and the animals were then sacrificed by cervical dislocation. The EGS were carefully prepared from rat jejunum as follows (28): the segment was quickly excised, stripped of adhering tissue and flushed several times with a Ringer solution (9\%) containing $0.154 \mathrm{mM} / 1 \mathrm{NaCl} ; 0.0034 \mathrm{mM} / 1 \mathrm{KCl}$; $0.0024 \mathrm{mM} / 1 ; \mathrm{HCO}_{3} \mathrm{Na}$ and $0.0021 \mathrm{mM} / 1 \mathrm{CaCl}_{2}$. The intestine was everted and immediately placed in an oxygenated medium $\left(\mathrm{O}_{2} / \mathrm{CO}_{2}, 95 \%: 5 \%\right)$ at $37 \pm 0.5{ }^{\circ} \mathrm{C}$. Then, it was cut into small sacs of $5 \mathrm{~cm}$ in length which were blotted and weighed; the average weight of the sacs was $0.3498 \pm$ $0.0264 \mathrm{~g}$. For the assays, the sacs were filled with Ringer solution (9\%o) ( $\mathrm{pH} 7.4)$, hanged in a test tube containing $15 \mathrm{ml}$ of the drug solution $(\mathrm{pH}$ 6.8) and incubated at $37 \pm 0.5^{\circ} \mathrm{C}$ in an oscillating water bath (OLS 200, Grant instruments, Cambridge, UK) at 60 cycles/min. Throughout the assay, the sacs were constantly oxygenated $\left(95 \% \mathrm{O}_{2}-5 \% \mathrm{CO}_{2}\right)$. Samples were withdrawn at the same times used with the bio-mimetic artificial membrane technique and assayed spectrophotometrically. The experiments were conducted 6 times for each drug. Drug absorption was expressed in percentage.

\section{Calculation of the Apparent Permeability Coefficients}

Permeability coefficients $\left(P_{a p p}\right)$ obtained with the Sartorius SM 16750 Absorption Simulator and the EGS method were calculated according to Eq. 1 (29):

$$
P_{a p p}=\frac{d Q}{d t} \times \frac{1}{A C_{0}}
$$

Where $P_{a p p}(\mathrm{~cm} / \mathrm{s})$ is the apparent permeability coefficient, $d Q / d t(\mu \mathrm{g} / \mathrm{s})$ the amount of drug permeated per unit of time calculated from the regression line of time points of sampling, $A$ $\left(\mathrm{cm}^{2}\right)$ the surface area available for permeation, and $C_{0}(\mu \mathrm{g} / \mathrm{ml})$ the initial drug concentration in the donor compartment.

\section{Percentage of Drug Recovery (R\%) and Drug Retention (Ad\%)}

At the end of each experiment, the residual concentration of drug remaining in the donor medium (Sartorius SM 16750 model) or in the external medium (EGS technique) was assayed. The percentage of drug retained $(\mathrm{Ad} \%)$ either by the artificial lipoid barrier or by the EGS was determined by a mass balance calculation according to Eq. 2:

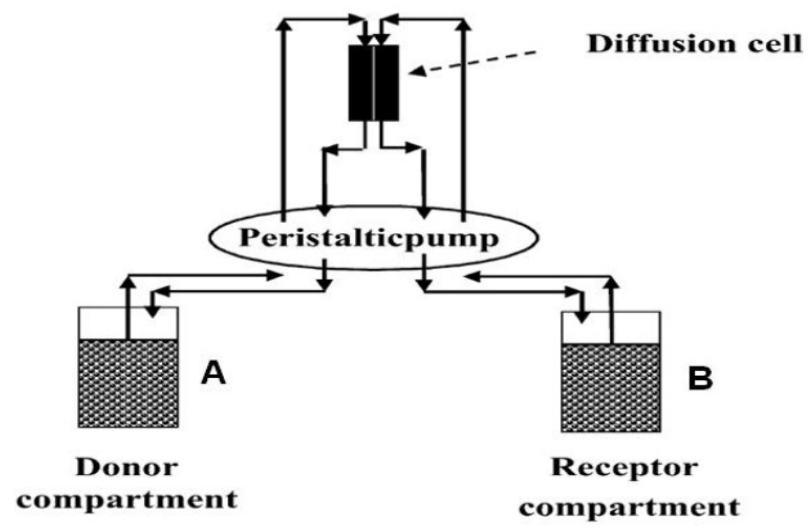

Figure 1. Schematic representation of the Sartorius SM 16750 Simulator Model 


$$
A d \%=100-R \%=\left(1-\frac{C_{r, \text { end }} \times V_{r}+C_{d, \text { end }} \times V_{d}}{C_{0} \times V_{r}}\right) \times 100
$$

where $\mathrm{C}_{\mathrm{r}, \text { end }}$ and $\mathrm{C}_{\mathrm{d} \text {,end }}$ are the drug concentrations measured at the end of the experiment in the receiver and donor compartments respectively, $\mathrm{C}_{\mathrm{d}, 0}$ the initial concentration in the donor compartment, and $V_{r}$ and $V_{d}$ the volumes of the receptor and donor compartments respectively.

\section{DRUG ANALYSIS}

A spectrophotometric method using a UV-Visible Thermo Scientific EVO 60 spectrophotometer was developed to quantify metformin $\left(\lambda_{\max }=230\right.$ $\mathrm{nm})$, clopidogrel $\left(\lambda_{\max }=240 \mathrm{~nm}\right)$, tramadol $\left(\lambda_{\max }\right.$ $=271 \mathrm{~nm})$, doxycycline $\left(\lambda_{\max }=274 \mathrm{~nm}\right)$, diclofenac $\left(\lambda_{\max }=276 \mathrm{~nm}\right)$, and chlorothiazide $\left(\lambda_{\max }=294 \mathrm{~nm}\right)$.

\section{Correlation Study between the two in vitro Models}

The correlation study between the Sartorius SM 16750 Absorption Simulator method and the EGS model was carried out by the means of a mathematical approach using two parameters: the difference factor $\left(f_{1}\right)$ and the similarity factor $\left(f_{2}\right)$. This model is usually used to compare dissolution profiles (30), but it can also be used to compare diffusion kinetics (31).

\section{Calculation of the Difference Factor $\left(f_{1}\right)(32)$}

This factor calculates the percent difference between two curves at each time point and is a measurement of the relative error between the two curves. It's determined according to Eq. 3:

$$
f_{1}=\left\{\left[\sum_{t=1}^{n}\left|R_{t}-T_{t}\right|\right] /\left[\sum_{t=1}^{n} R_{t}\right]\right\} \cdot 100
$$

n: number of time points.

$\mathbf{R}_{\mathbf{t}}$ : diffusion value of the reference batch at time $t$

$\mathbf{T}_{\mathbf{t}}$ : diffusion value of the test batch at time $\mathrm{t}$

\section{Calculation of the Similarity Factor $\left(f_{2}\right)(32)$ :}

This factor is a logarithmic reciprocal square root transformation of the sum of squared error and is a measurement of the similarity in percent diffusion between the two curves. It's calculated using Eq. 4:

$$
f_{2}=50 \cdot \log \left\{\left[1+(1 / n) \sum_{t=1}^{n}\left(R_{t}-T_{t}\right)^{2}\right]^{-0.5} \cdot 100\right\}
$$

The curves are considered similar when $f_{1}$ value is close to zero and $f_{2}$ value is close to 100 . Generally $f_{1}$ values up to $15(0-15)$ and $f_{2}$ values greater than $50(50-100)$ ensure equivalence of the two curves.

\section{STATISTICAL ANALYSIS}

Statistical analysis was computed with SPSS $^{\circledR}$ Windows (version 14.0). The results were represented as mean \pm Standard Deviation $( \pm \mathrm{SD})$ for the six experiments. For each drug compound, the apparent permeability average values $\left(\mathrm{P}_{\text {app }}\right)$ obtained for the two in vitro models were compared using a one way analysis of variance (ANOVA) test. Student's t-test was used to compare the two data sets of drug diffusion. The difference observed was considered significant at $\mathrm{p} \leq 0.05$.

\section{RESULTS}

Comparison of Drug Permeability Coefficients The apparent permeability coefficients $\mathrm{P}_{\text {app }}(\mathrm{cm} / \mathrm{s})$ of tramadol, doxycycline, diclofenac, clopidogrel, metformin and chlorothiazide obtained with the EGS method and the Sartorius SM 16750 Absorption Simulator Apparatus are shown in table 2. Data are expressed as mean \pm S.D. The EGS permeability coefficient of tramadol was $11,843 \pm 1,985 \mathrm{~cm} / \mathrm{s}$ at $\mathrm{pH}$ 6.8, which is significantly lower than the coefficient obtained with the Sartorius SM 16750 model $(28,022 \pm$ 
$4,793 \mathrm{~cm} / \mathrm{s})(\mathrm{p} \leq 0.05)$. Similar results were observed for doxycycline, clopidogrel and chlorothiazide with Sartorius SM 16750 permeability values higher than the EGS technique coefficients $(\mathrm{p} \leq 0.05)$. The EGS permeability coefficients were $14.351 \pm 2.012$ $\mathrm{cm} / \mathrm{s}, 2.589 \pm 0.426 \mathrm{~cm} / \mathrm{s}$ and $0.451 \pm 0.085 \mathrm{~cm} / \mathrm{s}$, whereas the Sartorius SM 16750 permeability values were $32,335 \pm 4,344 \mathrm{~cm} / \mathrm{s}, 7,693 \pm 1,331$ $\mathrm{cm} / \mathrm{s}$ and $0,814 \pm 0,077 \mathrm{~cm} / \mathrm{s}$ for doxycycline, clopidogrel and chlorothiazide respectively. On the other hand, diclofenac permeability coefficients obtained by EGS and Sartorius SM 16750 absorption models did not present a significant difference $(p>0.05)$. Similar results were noticed with metformin $(p>0.05)$. The EGS permeability coefficients were $17.044 \pm 2.914$ $\mathrm{cm} / \mathrm{s}$ and $0.737 \pm 0.149 \mathrm{~cm} / \mathrm{s}$ and the Sartorius SM 16750 permeability values were $19.667 \pm$ $2.879 \mathrm{~cm} / \mathrm{s}$ and $0.613 \pm 0.104 \mathrm{~cm} / \mathrm{s}$ for diclofenac and metformin respectively.
Percentage of Drug Recovery (R \%) Table 3 shows the percentages of drug recovery and drug retention of tramadol, doxycycline, diclofenac, clopidogrel, metformin and chlorothiazide with the Sartorius SM 16750 apparatus and the EGS model. Results are expressed as mean \pm S.D. With the first model, the percentages of drug retained were $1.79 \pm 1.05$ $\%, 4.00 \pm 1.36 \%, 2.44 \pm 1.16 \%, 1.25 \pm 1.32 \%$, $2.79 \pm 1.47 \%$ and $2.69 \pm 1.47 \%$, whereas, with the EGS technique, the percentages were $5.82 \pm$ $1.89 \%, 8.08 \pm 1.74 \%, 8.04 \pm 1.70 \%, 5.45 \pm$ $1.58 \%, 7.85 \pm 1.78 \%$ and $7.95 \pm 1.81 \%$ for tramadol, doxycycline, diclofenac, clopidogrel, metformin and chlorothiazide respectively. For the six drug assayed, the amount of the drug absorbed on the artificial membrane was less important than the amount retained on the EGS ( $p$ $\leq 0.05$ ). This may be explained by the fact that in the EGS model, drugs must cross the whole intestinal wall with a risk of accumulation in the muscular layer (9). In both cases, the percentages of drug retention were limited (below 10\%).

Table 2. Apparent permeability coefficients $\mathrm{P}_{\text {app }}(\mathrm{cm} / \mathrm{s})$ of tramadol, doxycycline, diclofenac, clopidogrel, metformin and chlorothiazide determined with the EGS and the Sartorius SM 16750 techniques.

\begin{tabular}{ccccccc}
\hline Compound & $\begin{array}{c}\text { Molecular } \\
\text { Weight } \\
(\mathrm{g} / \mathrm{mol})\end{array}$ & Solubility & Permeability & $\begin{array}{c}\mathbf{P}_{\text {app }}(\mathbf{E G S}) \\
\left(\mathrm{x} 10^{-6} \mathrm{~cm} / \mathrm{s}\right)\end{array}$ & $\begin{array}{c}\mathbf{P}_{\text {app }}(\mathbf{S a r t o r i u s}) \\
\left(\mathbf{x} 10^{-6} \mathrm{~cm} / \mathrm{s}\right)\end{array}$ & $\begin{array}{c}\text { Ratio } \\
(2)\end{array}$ \\
\hline Tramadol & 299.84 & High & High & $11.843 \pm 1.985$ & $28.022 \pm 4.793$ & 2.37 \\
Doxycycline & 512.90 & High & High & $14.351 \pm 2.012$ & $32.335 \pm 4.344$ & 2.25 \\
Diclofenac & 318.14 & Low & High & $17.044 \pm 2.914$ & $19.667 \pm 2.879$ & 1.15 \\
Clopidogrel & 419.90 & Low & High & $2.589 \pm 0.426$ & $7.693 \pm 1.331$ & 2.97 \\
Metformin & 165.63 & High & Low & $0.737 \pm 0.149$ & $0.613 \pm 0.104$ & 0.83 \\
Chlorothiazide & 317.71 & Low & Low & $0.451 \pm 0.085$ & $0.814 \pm 0.077$ & 1.81 \\
\hline
\end{tabular}

\begin{tabular}{|c|c|c|c|}
\hline $\begin{array}{c}\text { In vitro } \\
\text { absorption } \\
\text { model }\end{array}$ & Drug & $\begin{array}{l}\text { Percentage of drug } \\
\text { recovery } \pm \text { S.D (\%) }\end{array}$ & $\begin{array}{l}\text { Percentage of drug } \\
\text { retention } \pm \text { S.D }(\%)\end{array}$ \\
\hline \multirow{6}{*}{$\begin{array}{c}\text { Sartorius } \\
\text { apparatus }\end{array}$} & Tramadol & $98.21 \pm 1.05$ & $1.79 \pm 1.05$ \\
\hline & Doxycycline & $96.00 \pm 1.36$ & $4.00 \pm 1.36$ \\
\hline & Diclofenac & $97.56 \pm 1.16$ & $2.44 \pm 1.16$ \\
\hline & Clopidogrel & $98.75 \pm 1.32$ & $1.25 \pm 1.32$ \\
\hline & Metformin & $97.21 \pm 1.47$ & $2.79 \pm 1.47$ \\
\hline & Chlorothiazide & $97.31 \pm 1.47$ & $2.69 \pm 1.47$ \\
\hline \multirow{6}{*}{ EGS technique } & Tramadol & $94.18 \pm 1.89$ & $5.82 \pm 1.89$ \\
\hline & Doxycycline & $91.92 \pm 1.74$ & $8.08 \pm 1.74$ \\
\hline & Diclofenac & $91.96 \pm 1.70$ & $8.04 \pm 1.70$ \\
\hline & Clopidogrel & $94.55 \pm 1.58$ & $5.45 \pm 1.58$ \\
\hline & Metformin & $92.15 \pm 1.78$ & $7.85 \pm 1.78$ \\
\hline & Chlorothiazide & $92.05 \pm 1.81$ & $7.95 \pm 1.81$ \\
\hline
\end{tabular}


Correlation Study between the EGS Model and the Sartorius SM 16750 Apparatus

Figure 2 represents the absorption rates across the nitrocellulosic membrane used with the Sartorius SM 16750 Absorption Simulator ( $\bullet$ ) and the EGS $(\bullet)$ of tramadol $(1000 \mu \mathrm{M})$, doxycycline $(200 \mu \mathrm{M}), \quad$ diclofenac $(50 \mu \mathrm{M}), \quad$ clopidogrel $(232 \mu \mathrm{M})$, metformin $(1000 \mu \mathrm{M})$ and chlorothiazide $(1000 \mu \mathrm{M})$. Data are expressed as mean \pm S.D $(n=6)$.
The results for the calculation of the similarity factor $\left(f_{2}\right)$ and the difference factor $\left(f_{1}\right)$ are reported in table 4. For tramadol, $\left(f_{2}=70.11 \%\right.$ and $\left.f_{1}=49.79 \%\right)$, doxycycline $\left(f_{2}=63.79 \%\right.$ and $\left.f_{1}=80.66 \%\right)$, clopidogrel $\left(f_{2}=69.98 \%\right.$ and $f_{1}=$ $92.90 \%)$ and chlorothiazide $\left(f_{2}=74.99 \%\right.$ and $f_{1}=$ $45.01 \%) f_{2}$ and $f_{1}$ were higher than $50 \%$ and $15 \%$ respectively. However, for diclofenac $\left(f_{2}=\right.$ $74.96 \%$ and $\left.f_{1}=12.60 \%\right)$ and metformin $\left(f_{2}=\right.$ $82.52 \%$ and $\left.f_{1}=14.88 \%\right), f_{2}$ was higher than $50 \%$ and $f_{l}$ was less than $15 \%$.

\begin{tabular}{lcc}
\hline $\begin{array}{l}\text { Table } \mathbf{4} . \\
\text { metformin and chlorothiazide obtained with the EGS and the Sartorius SM 16750 models. }\end{array}$ \\
\hline Drug & Difference factor $\left(\boldsymbol{f}_{\mathbf{1}}\right) \mathbf{( \% )}$ & Similarity factor $\left(\boldsymbol{f}_{\mathbf{2}}\right) \mathbf{( \% )}$ \\
\hline Tramadol & 49.79 & 70.11 \\
Doxycycline & 80.66 & 63.79 \\
Diclofenac & 12.60 & 74.96 \\
Clopidogrel & 92.90 & 69.98 \\
Metformin & 14.88 & 82.52 \\
Chlorothiazide & 45.01 & 74.99 \\
\hline
\end{tabular}

\section{DISCUSSION}

Gastro-intestinal absorption is one of the key factors involved in the bioavailability of orally administered drug compounds. A great variety of in vitro, in situ and in vivo methods have been developed to assess the rate, extent and mechanism of intestinal absorption $(8,27,33)$. Several diffusion studies have been conducted using either the Sartorius SM 16750 Apparatus with a bio-mimetic artificial membrane or the EGS model.

The Sartorius SM 16750 Absorption Simulator is an in vitro model which simulates passive diffusion using an artificial lipoid membrane. The use of bio-mimetic artificial membrane techniques, such as used with the Sartorius SM 16750 Absorption Simulator method, offers several advantages. These techniques allow a rapid screening of a large number of compounds; they are simple to carry out; they are not expensive, and they avoid the use of animals or organs. Since the majority of drugs are mainly absorbed through passive transfer, the Sartorius SM 16750 Apparatus provides a suitable method for a variety of drugs and offers an effective approach for the assessment of drug absorption (34). Several diffusion studies were performed using this model with suitable and valuable results (35-37). The Sartorius SM 16750 Absorption Simulator used to perform the diffusion experiments presented the following characteristics: a donor and a receiver compartment adequately thermostated for a constant experimental temperature $\left(37 \pm 0.5^{\circ} \mathrm{C}\right)$; a peristaltic pump which allowed a regular, uniform and continuous circulation of both donor and receiver media assuring the dynamic conditions of the assay and avoiding the formation of undesired unstirred water layers at the level of the diffusion membrane; and an artificial lipoid membrane which was the essential part of this apparatus and which had comparable permeability with the natural gastro-intestinal barrier for passively transported substances. The nitrocellulose membrane was impregnated with a mixture of caprylic acid and lauryl alcohol (50\%-50\%) to mimic the intestinal barrier (34). Cellulose nitrate provided rigidity to the membrane whereas caprylic acid provided the hydrophilic character that exists in biological membranes, and lauryl alcohol was used to give the membrane a lipophilic character in order to simulate the intestinal barrier. It is important to notice that the variation in the composition of the lipidic phase used to soak the artificial membrane may affect significantly drug permeability (27). In our study, the lipidic phase proportions allowed to simulate the intestinal barrier and to give suitable results (34). The $0.45 \mu \mathrm{m}$ membrane pores were filled with the lipidic phase, so that lipid-soluble drugs could dissolve in the membrane, and then diffuse thanks to a concentration gradient across the lipidic pores whose sizes were significantly greater than the molecules. 


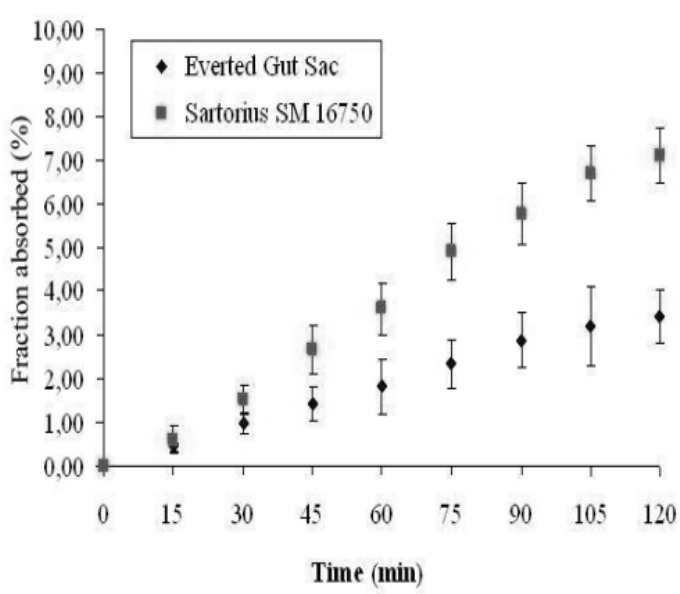

A

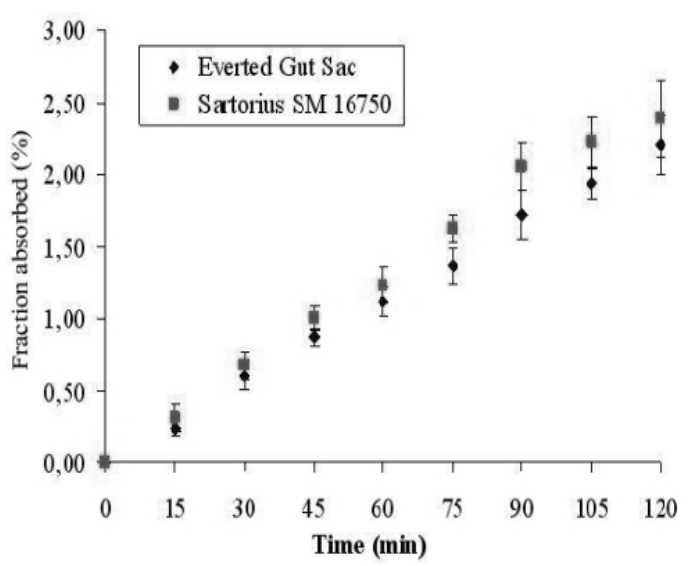

C

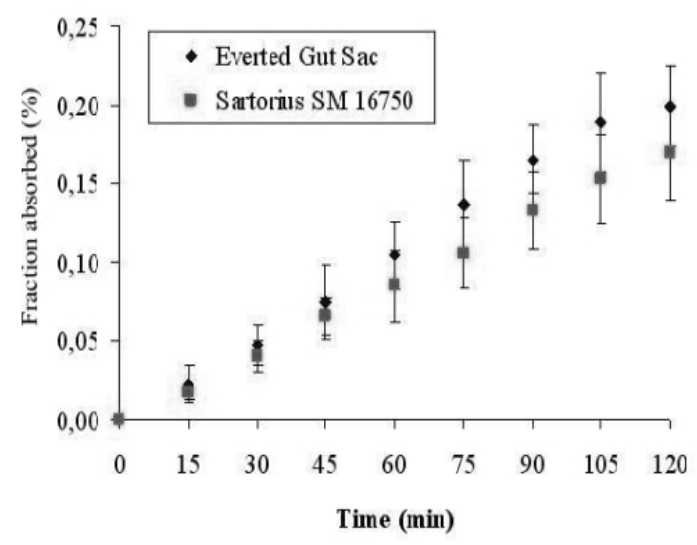

E

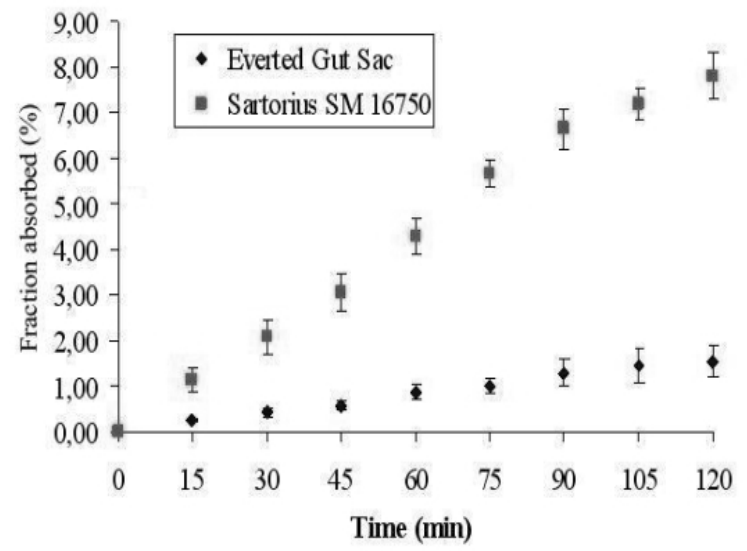

B

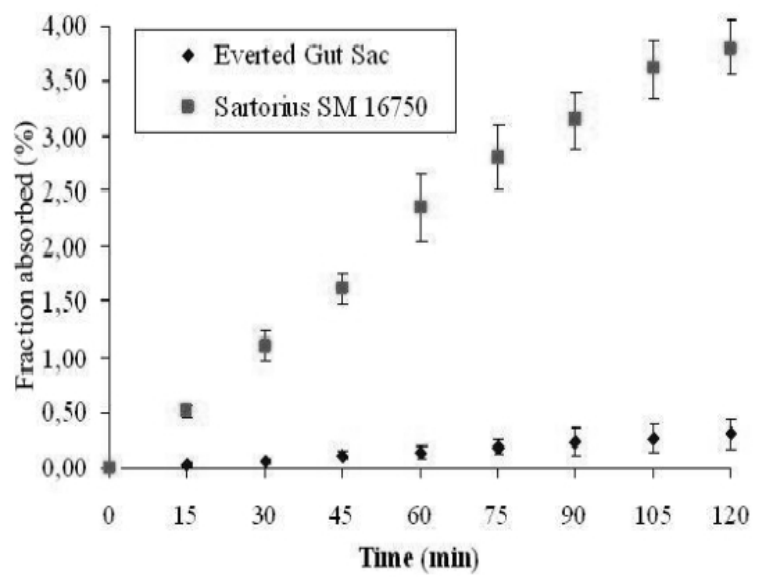

D

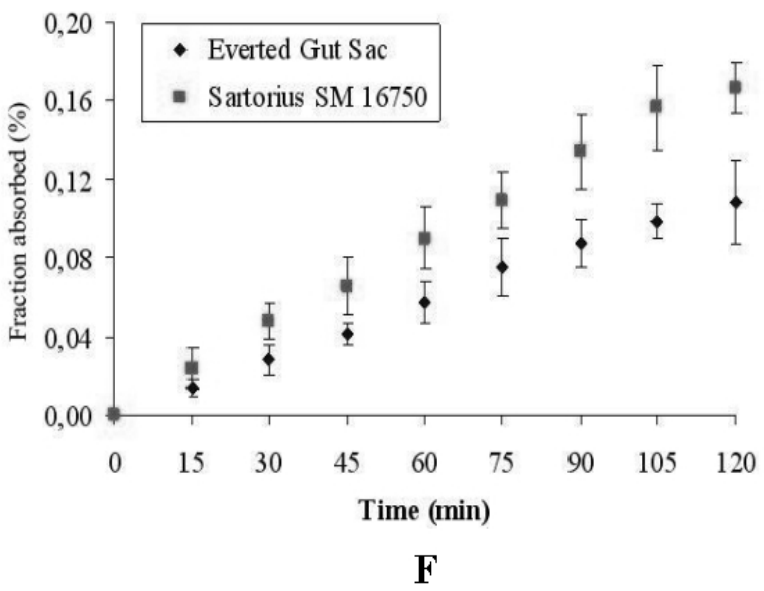

Figure 2. Absorption rates of drug compounds across the Sartorius SM 16750 (ㅍ) and the EGS (†) models: (A) Tramadol (1mM), (B) Doxycycline $(200 \mu \mathrm{M})$, (C) Diclofenac $(50 \mu \mathrm{M})$, (D) Clopidogrel $(232 \mu \mathrm{M})$, (E) Metformin $(1 \mathrm{mM})$ and $(\mathrm{F})$ Chlorothiazide $(1 \mathrm{mM})$. Data are expressed as mean \pm S.D $(\mathrm{n}=6)$.

The second in vitro model tested was the EGS of the rat small intestine. This technique has been used first to study the transport of macromolecules (38). Afterward, it was improved 
and used mainly to quantify the paracellular transport of hydrophilic molecules and to estimate the effects of potential enhancers on their absorption (39). This model was also used to study drug transport across the intestine (40), to determine kinetic parameters with high reliability and reproducibility $(\mathbf{8}, \mathbf{3 9})$, to study the mechanism of drug absorption, the uptake of liposomes and the effect of pharmaceutical excipients on drug absorption $(\mathbf{9}, \mathbf{4 1})$. The EGS method is considered as a valuable in vitro procedure for predicting the permeability characteristics of various drug classes (13) and studying the effect of efflux transporters, such as P-glycoprotein (P-gp), on xenobiotic transport through the intestinal barrier (42). EGS is a relatively fast and inexpensive method (9). During permeation experiments carried out with the EGS technique, the use of Ringer solution (9\%) associated with permanent oxygenation of the medium $\left(\mathrm{O}_{2} / \mathrm{CO}_{2}, \quad 95 \%: 5 \%\right)$ ensured tissue viability for up to 120 minutes. Under these conditions, histological studies have shown the validity of the everted intestinal segments after 2 hours of experiment (43).

Compared to the EGS model, the artificial membrane methods have some drawbacks. They do not take into consideration the potential role of enzymes, carrier-mediation (influx and efflux transporters), and pores which all reflect the active and the paracellular route in intestinal drug absorption $(\mathbf{3 4}, \mathbf{4 4}, \mathbf{4 5})$. In the EGS, all cell types and mucous layers are maintained (9); therefore, influx transporters such as oligopeptide transporters and bile acid transporters (46), efflux transporters like P-glycoprotein and multidrug resistance-associated proteins (MDR1 and MDR2) and the paracellular pathway still exist (47-49).

This study investigated the correlation between the Sartorius SM 16750 Absorption Simulator method and the EGS technique in assessing the in vitro permeability of six drug compounds. The drugs, which were selected across the BCS, were: tramadol and doxycycline (two highly soluble and highly permeable drugs), diclofenac and clopidogrel (two poorly soluble but highly permeable molecules), metformin (a highly soluble but poorly permeable drug), and chlorothiazide (a poorly soluble and poorly permeable compound).

By comparing the drug permeability coefficients obtained with the two in vitro models, it was found that the EGS apparent permeability coefficients $\left(\mathrm{P}_{\text {app }}\right)$ were lower than the Sartorius
SM 16750 Apparatus coefficients for 4 compounds: tramadol, doxycycline, clopidogrel and chlorothiazide $(p<0.05)$, whereas no significant differences in $\mathrm{P}_{\text {app }}$ were observed with diclofenac and metformin $(p>0.05)$. The comparison of diffusion profiles obtained with the two in vitro models showed that, for tramadol, doxycycline, clopidogrel and chlorothiazide, diffusion curves $(\%$ of drug absorbed per unit time) were not comparables since $f_{l}$ values were higher than $15 \%$. These results suggest passive transcellular diffusion is not the only mechanism for the passage of these molecules across the gastro-intestinal barrier and that other processes may be involved in their transport. For tramadol, the significant difference between the results can be explained by the possible involvement of uptake transporters in the intestinal transport and by the presence of transporters other than P-gP such as proton based efflux pumps implicated in limiting the transepithelial passage of this compound $(\mathbf{5 0}, \mathbf{5 1})$. Doxycycline's passage across the intestinal barrier occurs by a passive transcellular pathway mainly (22); however, the transepithelial transport of the drug is decreased by P-glycoprotein efflux pump (52, 53). Previous studies about clopidogrel showed that its absorption decreases by the intestinal efflux transporter P-glycoprotein $(\mathbf{5 4}, \mathbf{5 5})$. Finally, for chlorothiazide, previous studies reported that its main transport route was paracellular permeation (22). Besides, chlorothiazide's absorption seemed to be decreased by a non P-glycoprotein intestinal efflux transporter (25).

Diclofenac and metformin diffusion studies undertaken with the Sartorius SM 16750 Simulator apparatus and EGS method showed similar results in terms of permeability values ( $p>$ $0.05)$ and diffusion profiles $\left(f_{1}<15 \%\right.$ and $f_{2}>50 \%$ for both compounds). These results were expected for diclofenac since its passage across the intestinal epithelial cell layer occurs by passive diffusion (56). For metformin, a similarity in the results found with the two in vitro methods was noticed although metformin's passage through the intestinal barrier occurs mainly thanks to a paracellular mechanism (57, 58). Actually, metformin permeability is concentrationdependant, and the permeability tends to decrease when metformin concentration increases. In a previous study undertaken with Caco-2 cells model (58), it was reported that the predicted permeability of metformin showed a decrease by approximately $70 \%$ when drug concentration increased from 0.05 to $10 \mathrm{mM}$. This change was 
attributed to a decrease in the paracellular permeability (58).

During permeation experiments undertaken with the EGS and the Sartorius SM 16750 models, it was important to compare the percentage of drug recovery. Results showed that these percentages were high with the two models ( $>90 \%$ ), indicating that the amount of drug retained by the artificial membrane or the EGS was very limited. This phenomenon was reported previously (59).

\section{CONCLUSION}

In conclusion, the comparison between the performances of the Sartorius SM 16750 Absorption Simulator and the Everted Gut Sac technique in terms of predicting drug permeability showed a good correlation only for diclofenac and metformin. Whereas, the Sartorius SM 16750 gave an over-estimated apparent permeability $\left(\mathrm{P}_{\mathrm{app}}\right)$ for tramadol, doxycycline, clopidogrel and chlorothiazide compared to EGS model. This over-estimation can be explain by the fact that passive transcellular diffusion was not the only mechanism for the passage of these four molecules across the gastro-intestinal barrier and that other processes were involved in their transport (carrier-mediated transport and paracellular route). It could be concluded that the absorption simulator method, less invasive and easier to carry out, gives comparable results with the EGS technique only when drug passage across the intestinal barrier occurs by passive transcellular diffusion and when no influx or efflux systems are implicated in the transepithelial passage. The results of the study suggest that the Sartorius SM 16750 has limited application for the assessment of drug intestinal absorption compared to the EGS model.

\section{REFERENCES}

1. Busignies V, Chulia D, Choisnard L, DeChallemaison R, Gèse A, Stainmesse D, Siepmann J, Tchoreloff P, Viana M, Wehrlé P, Wouessidjewe D, Pharmacie galénique : Formulation et technologie pharmaceutique. Maloine, Paris, 2007.

2. Sugawara M, Kadomura S, He X, Takekuma Y, Kohri N, Miyazaki K. The use of an in vitro dissolution and absorption system to evaluate oral absorption of two weak bases in $\mathrm{pH}$-independent controlled-release formulations. Eur J Pharm Sci, 2005; 26:1-8.
3. Streubel A, Siepmann J, Bodmeier R. Drug delivery to the upper small intestine window using gastroretentive technologies. Curr Opin Pharmacol, 2006; 6:501-508.

4. Kararli TT. Gastrointestinal absorption of drugs. Crit Rev Ther Drug Carrier Syst, 1989; 6(1):3986.

5. Labaune JP. Pharmacocinétique. Masson: Paris, 1989.

6. Pade V, Stavchansky S. Link between drug absorption, solubility and permeability measurements in Caco-2 cells. J Pharm Sci, 1998; 87: 1604-1607.

7. Chhabra RS. Intestinal absorption and metabolism of xenobiotics. Envrion Health Perspect, 1979; 33: 61-69.

8. Barthe L, Woodley J, Houin G. Gastrointestinal absorption of drugs: methods and studies. Fundam Clin Pharmacol, 1999; 13:154-168.

9. Le Ferrec E, Chesne C, Artusson P, Brayden D, Fabre G, Gires P, Guillou F, Rousset M, Rubas W, Scarino ML. In Vitro Models of the Intestinal Barrier: The Report and Recommendations of ECVAM Workshop 46. ATLA, 2001; 29:649-668.

10. Bohets $H$, Annaert $P$, Mannens G, Van Beijsterveldt L, Anciaux $\mathrm{K}$, Verboven $\mathrm{P}$ Meuldermans W, Lavrijsen K. Strategies for absorption screening in drug discovery and development. Curr Top Med Chem, 2001; 1:367383.

11. Balimane PV, Chong S, Morrison RA. Current methodologies used for evaluation of intestinal permeability and absorption. J Pharmacol Toxicol Methods, 2000; 44: 301-312.

12. Hidalgo IJ. Assessing the absorption of new pharmaceutical. Curr Top Med Chem, 2001; 1: 385-401.

13. Sharma P, Varma M, Chawla H, Panchagnula R. Relationship between lipophilicity of BCS class III and IV drugs and the functional activity of peroral absorption enhancers. Il Farmaco, 2005; 60(11-12):870-873.

14. Avdeef A. High-throughput measurement of membrane permeability. In: Van de Waterbeemd $\mathrm{H}$, Lennernäs $\mathrm{H}$, Artursson $\mathrm{P}$, ed. Drug Bioavailability/Estimation of Solubility, Permeability, Absorption and Bioavailability. Wiley-VCH, Weinheim, pp 46-71, 2003.

15. Grond S, Sablotzki A. Clinical pharmacology of tramadol. Clin Pharmacokinet, 2004; 43(13):879923.

16. Riond JL, Riviere JE. Pharmacology and toxicology of doxycycline. Vet Hum Toxicol, 1988; 30(5):431-443.

17. Nisha CF, Swati CJ, Anuruddha RC, Bhanudas SK. Superdisintegrants, effect on three model drugs from different BCS classes. Research J Pharm and Tech, 2009; 2(2):335-337.

18. Jantratid E, Strauch S, Becker C, Dressman JB, Amidon GL, Junginger HE, Kopp S, Midha KK, Shah VP, Stavchansky S, Barends DM. Biowaiver 
Monographs for Immediate Release Solid Oral Dosage Forms: Doxycycline Hyclate. J Pharm Sci, 2010; 99(4):1639-1653.

19. Davies NM, Anderson KE. Clinical pharmacokinetics of diclofenac. Therapeutic insights and pitfalls. Clin Pharmacokinet, 1997; 33:184-213.

20. Moshfegh K, Redondo M, Julmy F, Wuillemin WA, Gebauer MU, Haeberli A, Meyer BJ. Antiplatelet effects of clopidogrel compared with aspirin after myocardial infarction: enhanced inhibitory effects of combination therapy. J Am Coll Cardiol, 2000; 36:699-705.

21. Chuasuwan B, Binjesoh V, Polli JE, Zhang H, Amidon GL, Junginger HE, Midha KK, Shah VP, Stavchansky S, Dressman JB, Barends DM. Biowaiver monographs for immediate release solid oral dosage forms: diclofenac sodium and diclofenac potassium. J Pharm Sc, 2009; 98(4):1206-1219.

22. Saitoh R, Sugano K, Takata N, Tachibana T, Higashida A, Nabuchi Y, Aso Y. Correction of permeability with pore radius of tight junctions in caco-2 monolayers improves the prediction of the dose fraction of hydrophilic drugs absorbed by humans. Pharm Res, 2004; 21(5):749-755.

23. Gesek FA, Friedman PA. Mechanism of calcium transport stimulated by chlorothiazide in mouse distal convoluted tubule cells. J Clin Invest, 1992; 90(2): 429-438.

24. Cheng CL, Yu LX, Lee HL, Yang CY, Lue CS, Chou $\mathrm{CH}$. Biowaiver extension potential to BCS Class III high solubility-low permeability drugs: bridging evidence for metformin immediaterelease tablet. Eur j Pharm ScI, 2004; 22(4):297304.

25. Ingels F, Beck B, Oth M, Augustijns P. Effect of simulated intestinal fluid on drug permeability estimation across Caco-2 monolayers. Int J Pharm, 2004; 274:221-232.

26. Amidon GL, Lennernas H, Shah VP, Crison JR. A Theoretical Basis for a Biopharmaceutic Drug Classification: The Correlation of In Vitro Drug Product Dissolution and In Vivo Bioavailability. Pharm Res, 1995; 12:413-420.

27. Corti G, Maestrelli F, Cirri M, Furlanetto S, Mura P. Development and evaluation of an in vitro method for prediction of human drug absorption. I-Assessment of artificial membrane composition. Eur J Pharm Sci, 2006; 27:346-353.

28. Khemiss F, Ghoul-Mazgar S, Moshtaghie AA, Saidane D. Study of the effect of aqueous extract of Grewia tenax fruit on iron absorption by everted gut sac. J Ethnopharmacol, 2006; 103:9098.

29. Ki MH, Choi MH, Ahn KB, Kim BS, Im DS, Ahn SK, Shin HJ. The efficacy and safety of clopidogrel resinate as a novel polymeric salt form of clopidogrel. Arch Pharm Res, 2008; 31(2):250258 .
30. Moore JW, Flanner HH. Mathematical comparaison of dissolution profiles. Pharm Tech, 1996; 20(6),64-74.

31. Noureddine N, Douki W, Chaumeil JC, Souad S. Libération et diffusion à travers une membrane artificielle de la théophylline à partir d'un system matriciel. Ann Pharm Fr, 2004; 62(5):343-347.

32. Food and Drug Administration (FDA). Guidance for Industry: Dissolution Testing of Immediate Release Solid Oral Dosage Forms [online]. Available at: http://www.fda.gov/downloads/ Drugs/GuidanceComplianceRegulatoryInformatio n/Guidances/ucm070237.pdf. Accessed on 24 December 2009.

33. Stewart BH, Chan H, Jezykb N, Fleisherb D. Discrimination between drug candidates using models for evaluation of intestinal absorption. Adv Drug Deliv Rev, 1997; 23:27-45.

34. Acquier R, Maillols H, Delonca H. Résorption in vitro: étude critique d'un modèle de diffusion à membrane. J Pharm Belg, 1983; 38:156-162.

35. Kata ML, Ambrus R, Aigner ZN. Preparation and Investigation of Inclusion Complexes Containing Nifluminic Acid and Cyclodextrins. J Incl Phenom Macro, 2002; 44:123-126.

36. Lado C, Hajdú M, Farkas E, Then M, Taba G, Szentmihályi K. Study on the transfer of components of Aetheroleum carvi and Aetheroleum foeniculi oils. Fitoterapia, 2005; 76(2):166-172.

37. Mura P, Capasso G, Maestrelli F, Furlanetto S. Optimization of formulation variables of benzocaine liposomes using experimental design. J Liposome Res, 2008; 18:113-125.

38. Wilson TH, Wiseman G. The use of sacs of everted small intestine for the study of the transference of substances from the mucosal to the serosal surface. J Physiol, 1954; 123:116-125.

39. Barthe L, Woodley JF, Kenworthy S, Houin G. An improved everted gut sac as a simple and accurate technique to measure paracellular transport across the small intestine. Eur J Drug Metab Pharmacokinet, 1998; 23:313-323.

40. Chowhan ZT, Amaro AA. Everted rat intestinal sacs as an in vitro model for assessing absorptivity of new drugs. J Pharm Sci, 1977; 66(9):12491253.

41. Lo Y1. Relationships between the hydrophiliclipophilic balance values of pharmaceutical excipients and their multidrug resistance modulating effect in Caco-2 cells and rat intestines. J Control Rel, 2003; 90:37-48.

42. Barthe L, Bessouet M, Woodley JF, Houin G. The improved everted gut sac: a simple method to study intestinal P-glycoprtoein. Int J Pharm, 1998; 173:255-258.

43. Marzougui N, Khemiss F, Moshtaghie AA, Saidane D. Effect of environmental strains of salmonella typhimurium on transfert of water and electrolytes in rat's intestine. J Food Agr Environ, 2006; 4(1):17-20. 
44. Miret S, Abrahamse L, Groene EM. Comparison of in vitro models for the prediction of compound absorption across the human intestinal mucosa. J Biomol Screen, 2004; 9: 598-606.

45. Mälkiä A, Murtomäki L, Urtti A, Kontturi K. Drug permeation in biomembranes: In vitro and in silico prediction and influence of physicochemical properties. Eur J Pharm Sci, 2004; 23: 13-47.

46. Dantzig AH, Hoskins JA, Tabas LB, Bright S, Shepard RL, Jenkins IL, Duckworth DC, Sportsman JR, Mackensen D, Rosteck PR, Skatrud PL. Association of intestinal peptide transport with a protein related to the cadherin superfamily. Science, 1994; 264: 430-433.

47. Hunter J, Hirst BH. Intestinal secretion of drugs: The role of P-glycoprotein and related drug efflux systems in limiting oral drug absorption. Adv Drug Deliv Rev, 1997; 25:129-157.

48. Kool M, Haas M, Scheffer GL, Scheper RJ, Eijk MJ, Juijn JA, Baas F, Borst P. Analysis of expression of cMOAT (MRP2), MRP3, MRP4, and MRP5, homologues of the multidrug resistance-associated protein gene (MRP1) in human cancer cell lines. Cancer Res, 1997; 57:3537-3547.

49. Takano M, Yumoto R, Murakami T. Expression and function of efflux drug transporters in the intestine. Pharmacol Ther, 2006; 109:137-161.

50. Kanaan M, Daali Y, Dayer P, Desmeules J. PIII-2. Lack of tramadol and its active metabolite Odesmethyl-tramadol interaction with Pglycoprotein. Clinical Pharmacology \& Therapeutics, 2005; 79:58-58.

51. Kanaan M, Daali Y, Dayer P, Desmeules J. Uptake/Efflux Transport of Tramadol Enantiomers and $O$-Desmethyl-Tramadol: Focus on $P$ Glycoprotein. Basic Clin Pharmacol Toxicol, 2009; 105(3):199-206.

52. Raju SS, Aiyar S. Verapamil reverses doxycycline resistance in E. coli. Asia Pac J Pharmacol, 2001; 15(3):75-76.

53. Dowling P. Pharmacogenetics: It's not just about ivermectin in collies. Can Vet J, 2006; 47(12):1165-1168.

54. Taubert D, Von Beckerath N, Grimberg G, Lazar A, Jung N, Goeser T, Kastrati A, Schömig A, Schömig E. Impact of P-glycoprotein on clopidogrel absorption. Clin Pharmacol Ther, 2006; 80(5):486-501.

55. Simon T, Verstuyft C, Mary-Krause M, Quteineh L, Drouet E, Méneveau N, Steg PG, Ferrières J, Danchin N, Becquemont L. Genetic Determinants of Response to Clopidogrel and Cardiovascular Events. N Engl J Med, 2009; 360(4):363-375.

56. Idkaidek NM, Jilani JA, Mansi IA. Evaluation of hydroxyethyldiclofenac intestinal absorption in rats. Saudi Pharm J, 2005; 13(4):158-163.

57. Nicklin P, Keates AC, Page T, Bailey CJ. Transfer of metformin across monolayers of human intestinal Caco-2 cells and across rat intestine. Int J Pharm, 1996; 128:155-162.

58. Proctor WR, Bourdet DL, Thakker DR. Mechanisms underlying saturable intestinal absorption of metformin. Drug Metab and Dispos, 2008; 36: 1650-1658.

59. Stamatialis DF, Rolevink HHM, Koops GH. Controlled transport of timolol maleate through artificial membranes under passive and iontophoretic conditions. J Control Rel, 2002; 81:335-345. 